\title{
Qualitative Impact Evaluation of a Social Marketing Campaign for Conservation
}

Gabrielle Salazar, Morena Mills, Diogo Veríssimo

Gabrielle Salazar Mailing Address:

Imperial College London, Silwood Park, Buckhurst Rd, Ascot SL5 7QN, UK

Morena Mills Mailing Address:

Imperial College London, Silwood Park, Buckhurst Rd, Ascot SL5 7QN, UK

Centre for Biodiversity and Conservation Science, The University of Queensland, St. Lucia 4072, Australia

Diogo Veríssimo Address:

Department of Zoology, University of Oxford, Oxford, UK

Oxford Martin School, University of Oxford, Oxford, UK

Institute for Conservation Research, San Diego Zoo Global, California, USA.

This article has been accepted for publication and undergone full peer review but has not been through the copyediting, typesetting, pagination and proofreading process, which may lead to differences between this version and the Version of Record. Please cite this article as doi: 10.1111/cobi.13218.

This article is protected by copyright. All rights reserved. 
Please address correspondence to:

Morena Mills, Imperial College London, Silwood Park, Buckhurst Rd, Ascot SL5 7QN, UK

Email: M.mills@imperial.ac.uk

Running Head: Social Marketing

Keywords: Rare Pride, theory-driven evaluation, general elimination methodology, parrot conservation, Bonaire

\section{ABSTRACT}

Social marketing campaigns use marketing techniques to influence human behavior for the greater social good. In conservation, social marketing campaigns have been used to influence behavior for the benefit of biodiversity as well as society. However, there are few evaluations of their effectiveness. We used General Elimination Methodology, a theorydriven qualitative evaluation method, to assess the long-term impacts of a social marketing campaign on human behavior and biodiversity. We evaluated a 1998 Rare Pride Campaign on the island of Bonaire, designed to increase the population of the lora (Amazona barbadensis), a threatened parrot species. To evaluate the campaign's impacts, we interviewed a range of stakeholder groups to understand their perceptions of the drivers of the changes in the lora population over time. We used this data to develop an overall Theory of Change to explain changes in the lora population by looking at the overlap in hypotheses within and between stakeholder groups. We then triangulated that Theory of Change with 
evidence from government reports, peer-reviewed literature, and newspapers. Our results suggest that the observed increase in the lora population can be largely attributed to a decrease in illegal poaching of loras and an associated decrease in local demand for pet loras. The decreases in both poaching and demand have likely been driven by a combination of law enforcement, social marketing campaigns (including the Rare campaign), and environmental education in schools. General Elimination Methodology proved to be an illuminating post-hoc evaluation method for understanding the complexity around how multiple interventions have influenced conservation outcomes over time. There is a need for evidence-based evaluations of social marketing interventions to ensure that limited resources are spent wisely. Here we present a new approach for evaluating the influences of social marketing campaigns on both human behavior and conservation outcomes.

\section{INTRODUCTION}

Human behavior is the underlying driver of the world's most pressing environmental problems, from climate change to habitat loss (Schultz 2011; Veríssimo 2013). To protect biodiversity, conservation efforts must do more than raise awareness, they must motivate changes in human behavior (Schultz 2011). One approach to influence human behavior is social marketing, which applies insights from marketing to change behaviors for the greater social good (Andreasen 1995). Social marketing has been widely applied in the health sector to address issues such as smoking and family planning (Cheng et al. 2011). It has also been used to promote sustainable behaviors and conservation actions, from recycling (McKenzieMohr, 2011) to fisheries management (Andriamalala 2013). Despite the use of social marketing in conservation, there are few rigorous evaluations of its effectiveness (Veríssimo 
et al. 2018). In order to decide whether to invest limited conservation funding in social marketing, it is critical to understand the degree to which social marketing campaigns influence both human behavior and the biodiversity they are trying to protect (Ferraro \& Pattanayak 2006).

The need for evaluation and evidence-based analysis is a priority, both in the social marketing field (Kotler \& Lee 2008) and in conservation (Sutherland et al. 2004; Baylis et al. 2016). While the conservation field has typically prioritized quantitative evaluation methods these methods can be resource intensive and require large sample sizes (Baylis et al. 2016) or baseline data that is unavailable (Bottrill et al. 2011). Quantitative methods also focus on the magnitude of an effect without revealing the underlying mechanisms that have led to that effect. In other fields, theory-driven qualitative evaluation methods have been developed to address the attribution of cause and effect where baseline data and sample sizes are limited (White 2012). Unlike "black box" evaluations, which only look at the outcome of interventions, theory-driven evaluations can help us understand how an intervention works by revealing the underlying processes that have led to observed outcomes (Chen 2012). General Elimination Methodology (GEM) is a theory-driven qualitative evaluation method that improves our understanding of cause and effect relationships by systematically ruling out alternative explanations for the outcome of interest (Scriven 2008; White 2012). Qualitative approaches, like GEM, offer an opportunity for the conservation sector to attribute causal effects to interventions, even in contexts were data is limited. Qualitative approaches can also help reveal the underlying mechanisms that lead to the outcome of interest, providing a more nuanced understanding of complex conservation issues.

Rare, a conservation non-governmental organization, has been using social marketing campaigns for over 30 years to change behavior and to promote biodiversity conservation in developing countries around the world (Jenks et al. 2010). There have been 
over 300 Rare Pride campaigns worldwide, all using a locally relevant flagship species (Rare 2017). Rare initially evaluated its programs through interviews with staff and local partners, having subsequently started using pre-post surveys and in some cases before-after-controlintervention experimental designs (Jenks et al. 2010; Veríssimo et al. 2018). However, the time frames of previous evaluations have been too short to measure impacts on biological targets, which may require longer recovery times.

We use GEM to evaluate the long-term impacts of a Rare Pride campaign that started in 1998 on Bonaire and used the yellow-shouldered Amazon parrot (Amazona barbadensis), locally known as 'lora,' as its flagship species (Scholtens \& Butler 1999). We aim to understand the extent to which the Rare campaign contributed to the observed increased in the lora population over the last twenty years. GEM involves 3 primary steps (Scriven 2008). First, identify the possible causes (e.g. decreased poaching) for the impact of interest (the increased population of lora on Bonaire). Second, identify the necessary conditions (e.g. existing environmental laws) for each possible cause to affect the impact of interest. Third, assess whether the conditions for each possible cause are present (e.g. were environmental laws regularly enforced). Rival explanations for what has led to the increase in the lora population over time were solicited from 8 stakeholder groups on Bonaire, resulting in an overall Theory of Change (TOC) that is supported by multiple stakeholder groups and that shows where the Rare Pride campaign fits into the larger history of lora conservation. This case study contributes to a gap in the conservation evaluation literature by providing an example of how theory-driven evaluation methods can be used to understand the long-term impacts of a conservation intervention. 


\section{METHODS}

This study took place on Bonaire, $12^{\circ} \mathrm{N}, 68^{\circ} \mathrm{W}$, a small Caribbean island $\left(288 \mathrm{~km}^{2}\right)$ that is part of the Kingdom of the Netherlands. Bonaire is home to the lora, a vulnerable parrot species which is threatened by poaching for the pet trade and habitat loss (BirdLife International 2017). The population of the lora had dropped to under 300 individuals in 1998, leading the government and local conservation groups to collaborate with Rare on a social marketing campaign to mitigate threats to the lora population. Since 1998, other interventions have taken place, including education programs, rehabilitation and release programs, and other campaigns (Fig. 1). Annual roost-counts since the campaign clearly show that the population has increased, with 294 loras recorded in 1998, 429 in 2008, and 1023 in 2018 (DCBD 2018), leading us to ask to what extent the Rare campaign contributed to this increase.

\section{Theory of Change Development}

Following the first two steps of GEM, we first identified the list of possible causes for the impact of interest and then determined whether the necessary conditions for each possible cause to affect the impact of interest were present. To identify the factors (e.g. interventions or events) that might have influenced the lora population, we reviewed the Rare Pride campaign report, websites of and reports by Bonaire's conservation organizations and government bodies and gray literature on loras (Supporting Information S1). We used these factors to develop a TOC to understand the causal pathways by which the Rare campaign might have influenced the lora population. 


\section{Participant Interviews}

The third step of GEM is to assess whether the conditions for each possible cause are present. To elicit further rival explanations and to test our TOC, we sought to interview a diverse set of participants from 8 stakeholder groups on Bonaire: veterinarians, biologists, tourism professionals, educators, government officials, media representatives, local residents and conservation professionals (including forestry game wardens and conservation organization employees). In selecting these groups, we attempted to strike a balance between relevance and diversity. To select participants, we used both purposive and snowball sampling. We first developed a list of key informants including volunteers from the original Rare campaign (Scholtens \& Butler 1999), leaders of conservation-related organizations, members of local government, and authors of reports (Supporting Information S1). Participants were sorted into groups based on their primary profession or volunteer role. The local residents group included individuals who did not have professional ties to the other groups (including farmers and former lora owners) but who were recommended as participants by at least 2 sources.

Our survey was divided into 3 parts (Supporting Information S2). The first part focused on the individual's background, their involvement with loras, their estimate of the current lora population, and their knowledge of current threats to loras. The second part tested our TOC by eliciting rival explanations for what has led to the change in the lora population since 1997. The third part focused on the impacts of the Rare campaign. Before conducting interviews, we piloted the survey on 2 individuals. We then added a question to elicit information on the relative influence of different factors perceived to have affected the lora population. 


\section{Theory of Change Testing}

To test our TOC, we created a card exercise using the factors we identified during the TOC development. Each participant was provided with a deck of cards with the factors as well as blank cards so they could add new factors if needed. Before each interview, we shuffled the cards to randomize them. We asked participants to sort the cards into 3 piles: A) factors that have affected the lora population since 1997; B) factors that have not affected the lora population since 1997; C) unsure/do not know. We used consistent prompts when participants asked for more information about cards (Supporting Information S3), and we asked follow-up questions to clarify points made during and after sorting.

To determine the relative influence of the factors that affected the population of loras, we removed all cards in piles $B$ and $C$ and asked participants to group the cards from pile $A$ on a scale of influence (from most influence on the left to least influence on the right). We then asked follow-up questions about how participants thought each intervention had affected the lora population and questions about the causal relationships between the different factors. We also asked questions specific to the participant's profession. Three participants were unable to complete the influence exercise due to time constraints or difficulty with the exercise. One interview was conducted simultaneously with 2 respondents and was treated as a single data point. After each card exercise, we photographed the piles to document card placement.

To look at how participants related the cards to one another, we recorded audio from all interviews with an Olympus LS-10 recorder, transcribed the interviews using OTRANSCRIBE and coded the interviews using NVIVO 11.3.2 to identify how interviewees 
described the causal pathways between different factors. We followed the Code of Ethics published by The Society for Conservation Biology and the study was approved by the Imperial College London Ethics Assessment (2016-01273848).

\section{Data Analysis}

We used descriptive statistics to analyze the answers to questions about the lora population and current threats to the lora. To summarize participants' estimates of the current lora population, we took the mid-point when a population range was given. For the population trend, we tallied responses into 3 categories: increased, decreased, or no change. To assess current threats faced by loras, we grouped responses into categories as defined by the IUCN Threats Classification Scheme Version 3.2 (IUCN 2012).

\section{Factors Perceived to Have Affected the Lora Population}

To analyze the card exercises, we counted the number of times a card was identified as having or not having affected the lora population since 1997. To quantify which factors had the most and least influence, we calculated the midpoint between the cards that were farthest apart on the influence scale and classified the cards as having: 1) most influence (left of the midpoint), 2) medium influence (intersected with the midpoint), 3) least influence (right of the midpoint).

To elicit each participant's TOC, we coded responses using deductive content analysis (Elo \& Kyngas 2007). Each of the 29 card topics was used as a separate code, one code was included for blank cards added by participants, and two additional codes were added through an iterative coding process (Supporting Information S3). We used Microsoft 
Excel Version 16 to summarize and chart each participant's responses to the 29 cards. In the chart, we noted whether participants perceived each factor to have had a positive or negative affect on the lora population and noted any causal links between different cards. To check the validity of our coding system, a second, independent researcher coded 5 randomly selected transcripts. We compared our coding for each interview and found an overall inter-coder reliability of $72 \%$, calculated by dividing the total number of agreements for all codes by the total number of agreements and disagreements for all codes combined (Campbell et al. 2013).

\section{Evidence Supporting the Factors that Have Affected the Lora Population}

We created an overall TOC for the campaign (Foundations of Success 2007) by triangulating responses within and between stakeholder groups. To be included in the overall TOC, a factor had to meet 2 criteria: 1) at least two-thirds of participants within a stakeholder group had to agree that the factor had affected the lora population since 1997 and on the

direction of the effect (e.g. positive or negative), and 2) at least 3 out of the 8 stakeholder groups had to agree that the factor had affected the lora population. To select this threshold, we first looked at different thresholds of agreement within groups (e.g. one-fourth, one-half, two-thirds, and three-fourths agree) and between groups (e.g. 3, 4, or 5 groups agree; Supporting Information S4). We selected a threshold of two-thirds agreement within groups because lower thresholds gave too much power to a single respondent in groups with only two respondents. For the between group threshold, we selected 3 groups or more because higher thresholds tended to exclude specialist knowledge as well as factors with fewer direct effects (Supporting Information S4). We eliminated factors that did not meet these criteria 
from further consideration, accepting that the lack of stakeholder support for these rival explanations meant they were unlikely to have played a major role.

Following the third step of GEM (Scriven 2008), we also assessed whether there was evidence that the conditions for each of the remaining factors to have an effect were present. To do this, we searched both Google and Google Scholar for each of the 12 positive factors using a minimum of 3 keywords or phrases related to each factor (Supporting Information S5). We reviewed the first 50 results for both search engines for each keyword. We focused on the 12 positive factors because we were interested in factors that may have led to the increase in the population described by the available species census data. We also reviewed documents shared with us by participants and reports published by Bonaire's conservation organizations (e.g. Openbaar Lichaam Bonaire 2010; Debrot et al. 2011). Additionally, we keyword searched 395 issues (April 2004 - May 2017) of The Bonaire Reporter, Bonaire's English newspaper, for the words 'lora' and 'parrot.'

\section{RESULTS}

\section{Theory of Change Development}

Through our review of the literature, we identified 29 factors that may have influenced the lora population over the last twenty years, including direct conservation interventions and economic changes on Bonaire. We used these factors to develop a TOC to understand the casual pathways by which the Rare Campaign and other factors could have influenced the lora population (Fig. 2). 


\section{Participant Interviews}

We identified 47 potential key informants for interviews and conducted 33 interviews in 2017. Thirty interviews took place in person and 3 took place via Skype. There were 14 female and 19 male participants, and they ranged in age from 19 to 87 with $45-54$ being the most common age bracket.

Of 33 respondents, 28 said that the lora population increased over the last twenty years, 2 said it decreased, 2 said it has not changed, and 1 respondent did not know. When asked for an estimate of the current lora population on Bonaire today, estimates ranged from 400 to $3000(n=24)$. Thirteen $(39 \%)$ respondents were within $20 \%$ of the latest published estimate at the time of 883 for 2016 (DCBD 2018).

When threats were sorted into the IUCN Threats Classification Scheme, $48 \%$ fell under Biological Resource Use, which includes persecution and poaching (Table 1). Seven responses were not specific enough to classify and were not included in the analysis.

Of the $24(72 \%)$ participants who remembered the Rare Campaign, 10 participants described it as a catalyst for other conservation interventions and 4 described its role in capacity building on Bonaire (2 participants described it as both). One participant said,

"I think it stimulated the government to do their thing. I think they needed this push... I think the Amnesty program would not have been possible at that moment without the Rare Program. Because then the time wouldn't have been ready. It would have maybe taken at least another 10 years or so, when it really got out of hand." 


\section{Theory of Change Testing}

\section{Factors Perceived to Have Affected the Lora Population}

Following GEM, we tested our TOC, identified factors perceived to have had an influence, and eliminated rival explanations for the observed increase in the lora population. The 29 cards were sorted into 3 categories (has affected, has not affected, and unsure) by all participants; participants also used the blank cards provided to add 7 additional factors, none of which overlapped. Out of the 29 factors listed on the cards, 18 factors were perceived to have affected the lora population with a threshold of two-thirds agreement within stakeholder groups and a minimum of 3 out of 8 stakeholder groups. Of these, 12 factors were perceived to have a positive effect and 6 factors were perceived to have a negative effect (Table 2). We did not find support for the 11 other factors, or rival explanations, that were in our original TOC, which included changes in government support of conservation and habitat restoration (Table 3). Additionally, no new rival explanations emerged through the interview process.

Of the 29 participants who said that poaching had affected the loras, 26 said that poaching had decreased since 1997. One participant commented,

". . I I think the diminishing of poaching had the most effect. And I think it was this combination of campaigns [Rare and Salba Nos Lora], which basically caused the diminishing of poaching pressure." 
The 5 cards that were most frequently placed on the most influence side of the scale were Pet Parrot Amnesty and Registration Program (19 times), Poaching of Loras (19 times), Echo (a local organization) (18 times), Salba Nos Lora Campaign (18 times), and Environmental Education in Schools (18 times).

\section{Evidence Supporting the Factors that Have Affected the Lora Population}

Following GEM, we determined whether there was evidence that the conditions for each of the remaining factors to have an effect were present. We focused our search on the 12 factors perceived to have a positive effect (Table 2) because these factors would have been most likely to increase the lora population. These factors included environmental education programs, social marketing campaigns, environmental laws and regulations, cooperation between conservation groups, nest box provision and nest cavity restoration, and the creation of local conservation organizations.

Evidence was found to support the influence of 9 of the positive factors and to reject the influence of one factor (provision of nest boxes); there was insufficient evidence to either confirm or reject the influence of 2 factors (Supporting Information S6). A detailed review of available evidence is in the Supporting Information and a selection is summarized here: Government reports show that the ratification of international nature conservation treaties in 1998 and 1999, including the Convention on International Trade in Endangered Species (CITES), forced the government to address illegal pet loras (Montanus 2000). This resulted in the Pet Parrot Amnesty and Registration Program, a mandatory registration of all pet loras (Montanus 2000). In 2002, 615 pet loras were ringed, after which any un-ringed loras were considered illegal (Montanus 2003). There is evidence that the enforcement of environmental laws increased after 2002, with nine separate confiscations of un-ringed loras 
reported on in The Bonaire Reporter (e.g. Williams 2011; Supporting Information S6). Additionally, in 2011, an independent firm evaluated Bonaire's Nature Policy and found that the majority of goals related to CITES and to environmental law enforcement had been achieved (Debrot et al. 2011). There is also evidence that ongoing social marketing campaigns reinforced an awareness of the laws and raised awareness about the lora's threatened status. For example, in 1999 , a survey of 570 residents found that $87 \%$ had been exposed to the Rare campaign and that $78 \%$ understood that loras were threatened (Scholtens \& Butler 1999). A 2002 education campaign by Salba Nos Lora resulted in 95\% of captive loras being registered (Montanus 2003) and there were follow-up campaigns between 2003 and 2009 (Openbaar Lichaam Bonaire 2010). The work of Rare, Salba Nos Lora, and Echo also resulted in frequent media coverage of the loras and related laws since 1997, including an ongoing column called ParrotWatch in The Bonaire Reporter (Supporting Information S6). Starting in 1997, environmental education in schools reinforced the message about the lora's threatened status (STINAPA 2017). Reports show that all schools on Bonaire were visited during the Rare Campaign to promote lora conservation (Scholtens \& Butler 1999) and that lora-related activities are still part of the annual curriculum for Grade 3 school children (STINAPA 2017). There is also evidence of conservation groups supporting lora conservation by collaborating on enforcement (DeSalvo \& DeSalvo 2007) and behavior change campaigns (Scholtens \& Butler 1999).

Evidence found in the literature review is also supported by interview respondents (Supporting Information S7). Some noted the importance of the campaigns in galvanizing government action and enforcement, 
“. . . it's those three things: the Pride Campaign made it possible for the Amnesty to happen, and then the amnesty made it possible for the enforcement to happen."

Respondents also noted the importance of the ongoing campaigns and environmental education,

"With continuity, by being there, by campaigning and by just standing their ground . . . just like what we're doing with education in schools."

A number of participants attributed the decrease in local demand to an improved awareness of the laws, with one saying,

“. . the primary most effective thing has been the perception that it's sort of an illegal activity and that you know people who keep parrots as pets, they don't want to keep parrots as pets enough to break the law."

Using GEM, we reduced our original TOC, which included 29 factors, to a final TOC that includes 11 positive factors and three causal pathways (Fig. 3). To create this TOC, only the positive factors (12) were considered; of the positive factors, one was excluded based on evidence, leaving only 11 factors for inclusion. The final TOC includes 9 positive factors that were triangulated by participants and supported by available evidence and 2 positive factors (the decrease in poaching and the decrease in local demand for pet loras) for which direct 
evidence was unavailable. We found that the observed increase in the lora population can be largely attributed to the decrease in poaching and the concomitant decrease in local demand for pet loras. Three causal pathways have led to this decrease over the last 20 years: law enforcement, environmental education in schools, and social marketing campaigns. Unfortunately, it is not possible to determine the relative contribution of each causal pathway due to the lack of more detailed data on the implementation of these different activities.

\section{DISCUSSION}

In this study, we evaluated whether social marketing campaigns can have long-term impacts on human behavior and conservation outcomes. Our findings suggest that law enforcement, a suite of social marketing campaigns, and youth environmental education all contributed to the increase in the lora population on Bonaire over the last twenty years. They also suggest that the social marketing campaigns contributed to this increase by helping to change behaviors towards loras, by shifting social norms and by increasing compliance with existing environmental laws. The campaigns also helped build local capacity for conservation, which increased the sustainability of behavior change efforts over the long term. Using GEM, we produced a TOC that was supported by diverse stakeholder groups and by data available in the literature.

Our results suggest that social marketing campaigns can change human behavior by supporting environmental laws and regulations, as found by Kennedy (2010). On Bonaire, social marketing campaigns helped support compliance with existing environmental laws, even when active enforcement was sporadic. It is possible that outreach surrounding laws and illegal behaviors influences behavior by signaling to individuals that the illegal behavior 
is not the accepted norm. A study by Nkonya et al. (2008) found that compliance is higher both when people are more aware of environmental laws and when laws are enacted by a local council, suggesting that compliance may be higher when laws are locally designed. Andriamalala et al. (2013) found a similar pattern in Madagascar, where a social marketing campaign helped to shift social norms and to build support for local environmental laws, resulting in a decrease in destructive fishing practices. These findings are important because resources for conservation are limited and practitioners need cost effective techniques that maximize compliance (Keane et al. 2008).

Information, by itself, does not typically change human behavior (Schultz 2011). However, people are influenced by social norms and by the behavior of others (Cialdini \& Trost 1998; Schultz 2011). On Bonaire, our results suggest that the combination of social marketing campaigns and youth environmental education programs helped shift social norms and behaviors towards loras over a 20-year period. Ardoin (2009) suggests that an integration of these strategies may be the most effective way to sustain behavior change.

It was not possible for us to separate the influence of the Rare Campaign from the influence of the other social marketing campaigns because ongoing campaigns often blended together, and some interviewees confused the different campaigns. It was also challenging to find individuals who had been on Bonaire for long enough to have experienced the campaigns, which limited our ability to find enough stakeholders to fill certain groups (e.g. customs officials). However, our results show that the suite of campaigns influenced the lora population by shifting social norms, by changing behaviors towards loras, and by increasing compliance with environmental laws. Our results also support the role of the campaigns in local capacity-building on Bonaire. For example, participants noted that the Rare campaign spurred the government into action, paved the 
way for the Pet Parrot Amnesty program, and built capacity for future environmental education and other social marketing efforts.

While there is a growing body of literature on the impacts of social marketing campaigns on conservation (Andriamalala et al. 2013; Veríssimo et al. 2018), most evaluations take place in the short-term and measure impacts on human behavior rather than biodiversity outcomes. Our results contribute to the literature by showing how social marketing campaigns can influence both human behavior and biodiversity, and how they interact with other interventions. Our research also contributes to the literature by providing an example of how qualitative methods can be used to efficiently understand causal attribution, as carrying out a similar study using quantitative methods would have required a much costlier large-scale and long-term research effort. Retrospective, long-term evaluations are important because impacts often occur outside the timeframe of conservation projects and because behavior change can be short-lived (De Young 1993).

\section{Considerations for Future Uses of GEM}

This study represents the first post-hoc evaluation of a social marketing campaign aimed at biodiversity conservation using GEM. One of the strengths of GEM is that it minimizes common biases encountered by evaluators. Firstly, GEM minimizes "similarperson bias," or the tendency to seek out respondents with whom one agrees, by forcing the evaluator to seek out hypotheses from different groups (White 2012). GEM also minimizes "courtesy bias," where the respondent tells you what you want to hear, by considering the factor of interest (e.g. the Rare Campaign) as one of many possible causes of the impact of interest (e.g. the increase in the lora population) rather than asking directly about the factor 
of interest (White 2012). GEM also reveals knowledge gaps in a system, as in the case of illegal poaching and local demand for pet loras on Bonaire.

In the future, GEM could be used to evaluate other Rare campaigns. It would be interesting to test GEM in locations where follow-up social marketing campaigns have not taken place, to see if Rare campaigns make a long-term difference on their own. Future comparative research could also use GEM to evaluate the case of Amazona barbadensis on Margarita Island, Venezuela, where the parrot population has also increased over the last 20 years (Rojas-Suárez and Rodríguez 2015). Although we do not know what has driven the increase, ongoing education programs and outreach campaigns have taken place on the island (Rojas-Suárez and Rodríguez 2015). Any future case studies would need to have sufficient baseline data on the flagship species in question.

Qualitative evaluation approaches, like GEM, offer an opportunity for the conservation community to learn from a wider range of conservation projects. It is not always feasible or desirable to carry out robust quantitative impact evaluations, which often require significant resources (Baylis et al. 2016). In contrast, qualitative methods can be used with less investment of time and money. Unlike quantitative methods, which often focus on the impact of an individual element or intervention, methods such as GEM also provide insight into the complexity of a case study and the interactions between the mechanisms that lead to conservation outcomes.

There are also limitations of GEM that should be addressed in future research. Firstly, while GEM outlines a set of logical steps to guide evaluations (Scriven 2008), the choice of tools is up to the evaluator (White 2012). A number of decisions had the potential 
to influence results and should be considered in future applications of the methodology. Firstly, when asking respondents to evaluate rival explanations, it is important to select factors that do not overlap. Secondly, we chose to triangulate the responses of different groups to increase efficiency in terms of time and to elicit a common vision for what has affected the lora population. This method of triangulation risks ignoring hypotheses put forward by one or a handful of participants. The selection of higher thresholds of agreement also has the potential to exclude experiential or specialist knowledge from the TOC.

There is a clear need for evidence-based evaluations of social marketing interventions in conservation to ensure that limited resources are spent wisely (Sutherland 2004). Here we present GEM as one new method for evaluating the influences of social marketing campaigns on both human behavior and conservation outcomes.

\section{ACKNOWLEDGMENTS}

We would like to thank all of the individuals and organizations on Bonaire who participated in this study. Special thanks to P. Montanus, H. Anthony, H. DeWit, and F. DeWit for their support, and to Echo, the Dutch Caribbean Nature Alliance, and the Rotary Club for the connections they provided on Bonaire.

This article is protected by copyright. All rights reserved. 


\section{LITERATURE CITED}

Andreasen A. 1995. Marketing social change: Changing behavior to promote health, social development, and the environment. Jossey-Bass, San Francisco, California.

Andriamalala G, Peabody S, Gardner CJ, Westerman K. 2013. Using social marketing to foster sustainable behavior in traditional fishing communities of southwest Madagascar. Conservation Evidence 10:37-41. Available from http://www.conservationevidence.com/collection/25.

Ardoin N. 2009. Behavior change theories and free-choice environmental learning. Pages 57-76 in Falk JH, Heimlich JE, Foutz S, editors. Free-choice learning and the environment. AltaMira Press, Plymouth, United Kingdom.

Baylis K, Honey-Rose's J, Borner J, Corbera E, Ezzine-de-Blas D, Ferraro PJ, Lapeyre R, Persson UM, Pfaff A, Wunder S. 2016. Mainstreaming impact evaluation in nature conservation. Conservation Letters 9:58-64. DOI:10.1111/conl.12180.

BirdLife International. 2017. Amazona barbadensis. The IUCN Red List of Threatened Species 2017. Available from http://dx.doi.org/10.2305/IUCN.UK.20171.RLTS.T22686325A110628721.en (accessed August 2017).

Bottrill M, Hockings M, Possingham H. 2011. In pursuit of knowledge: addressing barriers to effective conservation evaluation. Ecology and Society 16:14. Available from http://www.ecologyandsociety.org/vol16/iss2/art14/.

Campbell JL, Quincy C, Osserman J, Pedersen OK. 2013. Coding In-depth Semistructured Interviews: Problems of Unitization and Intercoder Reliability and Agreement. Sociological Methods \& Research 42:294-320. 
Chen HT. 2012. Theory-driven evaluation: Conceptual framework, application and advancement. Pages 17-40 in Strobl R, Lobermeier O, Heitmeyer W, editors. Evaluation von Programmen und Projekten für eine demokratische Kultur. Springer, Wiesbaden, Germany.

Cheng H, Kotler P, Lee, N. 2011. Social Marketing for Public Health: Global Trends and Success Stories. Jones \& Bartlett Learning, Burlington, Massachusetts, USA.

Cialdini RB, Trost MR. 1998. Social influence: Social norms, conformity, and compliance. Pages 151 -102 in DT Gilbert, ST Fiske, and G Lindzey, editors. The handbook of social psychology. 4th edition, Volume 2. McGraw-Hill, New York.

DCBD (Dutch Caribbean Biodiversity Database). 2018. Yellow-shouldered parrot counts: Number of parrots in roosts on Bonaire (1980 - 2018). Bonaire, Netherlands Antilles. Available from http://www.dcbd.nl/monitoring/yellow-shouldered-parrot-counts (accessed January 2017).

Debrot AO, de Graaf M, Henkens R, Meesters HWG, Slijkerman DME. 2011. A status report of nature policy development and implementation in the Dutch Caribbean over the last 10 years and recommendations towards the Nature Policy Plan 2012 - 2017. Report number C065/11. Institute for Marine Resources \& Ecosystem Studies, Wageningen, The Netherlands. Available from https://www.wur.nl/en/Publicationdetails.htm?publicationld=publication-way-343131363438 (accessed July 2017).

DeSalvo L, DeSalvo G. 2007. Flotsam and Jetsam. The Bonaire Reporter, Bonaire, The Netherlands Antilles. 26 January 2007: 4. Available from http://ufdc.ufl.edu/UF00094093/00339/allvolumes (accessed July 2017). 
De Young R. 1993. Changing Behavior and Making it Stick: The Conceptualization and Management of Conservation Behavior. Environment and Behavior 25:485-505.

Elo S, Kyngäs H. 2008. The qualitative content analysis process. Journal of Advanced Nursing 62:107-115.

Ferraro PJ, Pattanayak SK. 2006. Money for nothing? A call for empirical evaluation of biodiversity conservation investments. PLoS Biology 4 (e105)

DOI:10.1371/journal.pbio.0040105.

Foundations of Success. 2007. Using Results Chains to Improve Strategy Effectiveness. An FOS How-To Guide. Foundations of Success, Bethesda, Maryland, USA. Available from http://www.fosonline.org/resource/using-results-chains (accessed November 2017).

IUCN (International Union for the Conservation of Nature). 2012. Threats Classification Scheme (Version 3.2). Available from http://www.iucnredlist.org/technicaldocuments/classification-schemes/threats-classification-scheme (accessed July 2017).

Jenks B, Vaughan PW, Butler PJ. 2010. The evolution of Rare Pride: Using evaluation to drive adaptive management in a biodiversity conservation organization. Evaluation and Program Planning 33:186-190.

Keane A, Jones JP, Edwards-Jones G, Milner-Gulland EJ. 2008. The sleeping policeman: understanding issues of enforcement and compliance in conservation. Animal Conservation 11:75-82.

Kennedy AL. 2010. Using community-based social marketing techniques to enhance environmental regulation. Sustainability 2:1138-1160. DOI:10.3390/su2041138 
Kotler P, Lee NR. 2008. Social marketing: Influencing behaviors for good. $3^{\text {rd }}$ ed. Sage, Thousand Oaks, California.

McKenzie-Mohr D. 2011. Fostering sustainable behavior: An introduction to communitybased social marketing. $3^{\text {rd }}$ edition. New Society Press, British Columbia, Canada.

Montanus P. 2003. Handhavingsplan bescherming Lora. Openbaar Lichaam Bonaire, Bonaire, Netherlands Antilles.

Montanus P. 2000. Voorlichtingsplan Loraregistratie. Openbaar Lichaam Bonaire, Bonaire, Netherlands Antilles.

Nkonya E, Pender J, Kato E. 2008. Who knows, who cares? The determinants of enactment, awareness, and compliance with community Natural Resource Management regulations in Uganda. Environment and Development Economics 13:79-101.

Openbaar Lichaam Bonaire. 2010. Evaluatierapport Natuurbeleidsplan Bonaire 1999 - 2004. Openbaar Lichaam Bonaire, Bonaire, Dutch Caribbean.

Rare. 2017. Pride Campaigns. Rare, Arlington, Virginia, USA. Available from https://www.rare.org/pride\#.WYci11KZOgQ (accessed July 2017).

Rodríguez JP, Rojas-Suárez F. 2015. Libro Rojo de la Fauna Venezolana. 4th Edition. Provita y Shell Venezuela, S.A., Caracas, Venezuela. Available from http://animalesamenazados.provita.org.ve (accessed July 2018)

Scholtens E, Butler P. 1999. Learning About the Lora: A Campaign to Promote Pride in Bonaire's Yellow Shouldered Parrot. Rare, Arlington, Virginia, USA. Available from http://www.rareplanet.org/sites/rareplanet.org/files/BONAIRE.pdf (accessed February 2017).

Schultz PW. 2011. Conservation means behavior. Conservation Biology 25:1080-1083. 
Scriven M. 2008. A summative evaluation of RCT methodology: and an alternative approach to causal research. Journal of Multidisciplinary Evaluation 5:11-24. Available from http://journals.sfu.ca/jmde/index.php/jmde_1/article/view/160.

STINAPA Bonaire (De Stichting Nationale Parken Bonaire). 2017. Nature and Environment Education. STINAPA, Bonaire, Netherlands Antilles. Available from http://stinapabonaire.org/school-programs/ (accessed July 2017).

Sutherland. 2004. The need for evidence-based conservation. Trends in Ecology and Evolution 19:305-308.

Veríssimo D, Bianchessi A, Arrivillaga A., Cadiz FC, Mancao R, Green K. 2018. Does it work for biodiversity? Experiences and challenges in the evaluation of social marketing campaigns. Social Marketing Quarterly 24: 18-34

Veríssimo D. 2013. Influencing human behavior: an underutilised tool for biodiversity management. Conservation Evidence 10:2931. Available from http://www.conservationevidence.com/individual-study/5190.

Williams SR. 2011. Another Illegal Lora is Saved. The Bonaire Reporter, Bonaire, The Netherlands Antilles. 19 August 2011:8. Available from http://ufdc.ufl.edu/UF00094093/00339/allvolumes (accessed July 2017).

White H, Phillips D. 2012. Addressing attribution of cause and effect in small $n$ impact evaluations: towards and integrated framework. International Initiative for Impact Evaluation, Working Paper 15. New Delhi, India. Available from http://www.3ieimpact.org/media/filer_public/2012/06/29/working_paper_15.pdf (accessed July 2017). 


\section{TABLES}

(1)
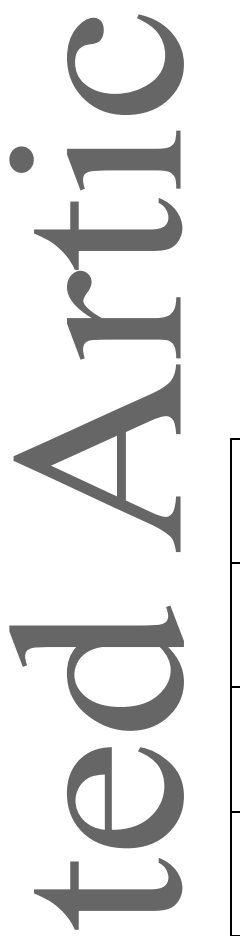

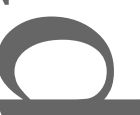

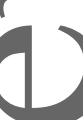

e

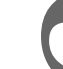

\begin{tabular}{|l|l|}
\hline Category of Threat & No. of Responses \\
\hline Biological resource use (e.g. poaching or persecution) & 36 \\
\hline Climate change and severe weather & 14 \\
\hline Invasive and other problematic species, genes \& diseases & 12 \\
\hline Residential and commercial development & \\
\hline Transportation and service corridors & 7 \\
\hline Pollution & 2 \\
\hline Other & 1 \\
\hline
\end{tabular}

This article is protected by copyright. All rights reserved. 
Table 2: Factors that were perceived to have affected the population of the lora, or yellowshouldered Amazon parrot, on Bonaire since 1997 by at least of 3 out of 8 stakeholder groups surveyed (at least two-thirds of the participants within each group also had to agree that the factor was important).

\begin{tabular}{|l|l|}
\hline Factors with a Positive Effect & Factors with a Negative Effect \\
\hline Convention on International Trade in Endangered Species & Development on Bonaire \\
\hline Cooperation between conservation groups & Environmental events \\
\hline Echo (local non-profit organization) & International trade \\
\hline Enforcement of environmental laws & Invasive species \\
\hline Environmental education in schools & Habitat loss \\
\hline Junior Ranger program & Human-parrot conflict \\
\hline Decrease in local demand for pet loras & \\
\hline Pet Parrot Amnesty/Registration Program & \\
\hline Decrease in poaching & \\
\hline Nest box provision/nest cavity restoration & \\
\hline & \\
\hline & \\
\hline & \\
\hline & \\
\hline & \\
\hline & \\
\hline & \\
\hline & \\
\hline
\end{tabular}

This article is protected by copyright. All rights reserved. 
Table 3: Factors that were not perceived to have affected the population of the lora, or yellow-shouldered Amazon parrot, on Bonaire since 1997 and were eliminated from further consideration following General Elimination Methodology.

\begin{tabular}{|l|}
\hline Factors Eliminated from Theory of Change \\
\hline A conservation champion (i.e. an influential individual) \\
\hline Bonaire becomes part of the Netherlands (2010) \\
\hline Business involvement in conservation \\
\hline Change in government support of conservation \\
\hline Change in size/influence of STINAPA (local conservation organization) \\
\hline Creation of the Dutch Caribbean Nature Alliance (2005) \\
\hline Ecotourism on Bonaire \\
\hline Invasive species eradication \\
\hline National pride in loras \\
\hline Reforestation and habitat restoration \\
\hline Rehabilitation and release of captive loras \\
\hline
\end{tabular}

This article is protected by copyright. All rights reserved. 


\section{FIGURE LEGENDS}

Figure 1: A timeline of important interventions and events that have influenced the conservation of the lora, or yellow-shouldered Amazon parrot, on Bonaire.

Figure 2: The original theory of change developed to understand the casual pathways by which the Rare Campaign and other factors could have influenced the lora population on Bonaire since 1997.

Figure 3: An overall Theory of Change showing the factors that have led to the increase in the population of the lora, or yellow-shouldered Amazon parrot, on Bonaire since 1997. This theory of change is based on our interviews and is supported by at least 3 out of 8 stakeholder groups and two-thirds of members within each group. The theory has also been triangulated with available evidence from government reports, peer-reviewed literature, and newspapers; evidence was not found to directly support elements displayed with a jagged edge.

This article is protected by copyright. All rights reserved. 


\section{FIGURES}

Figure 1:

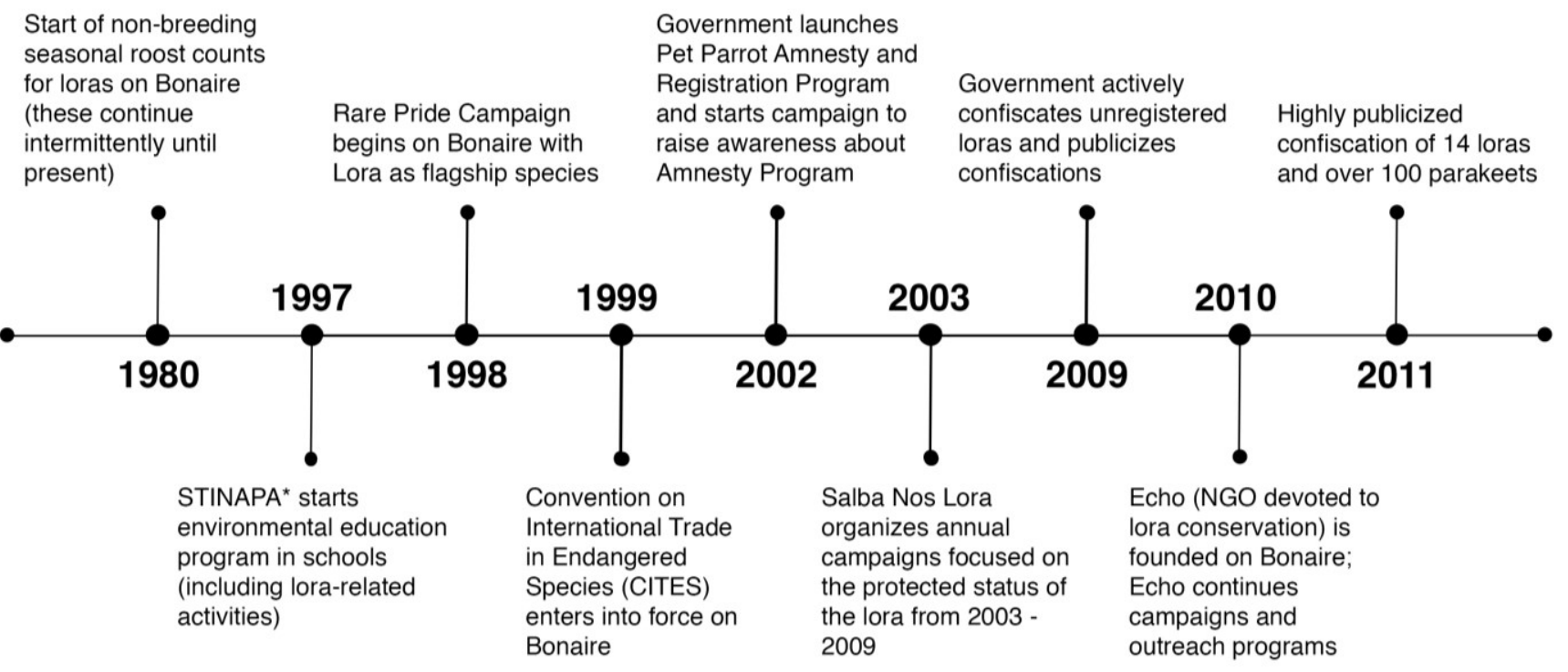

* Stichting Nationale Parken Bonaire (STINAPA Bonaire) is the non-governmental, nonprofit foundation that manages the two protected areas of Bonaire

Figure 1: A timeline of important interventions and events that have influenced the conservation of the lora, or yellow-shouldered Amazon parrot, on Bonaire.

This article is protected by copyright. All rights reserved. 
Figure 2:

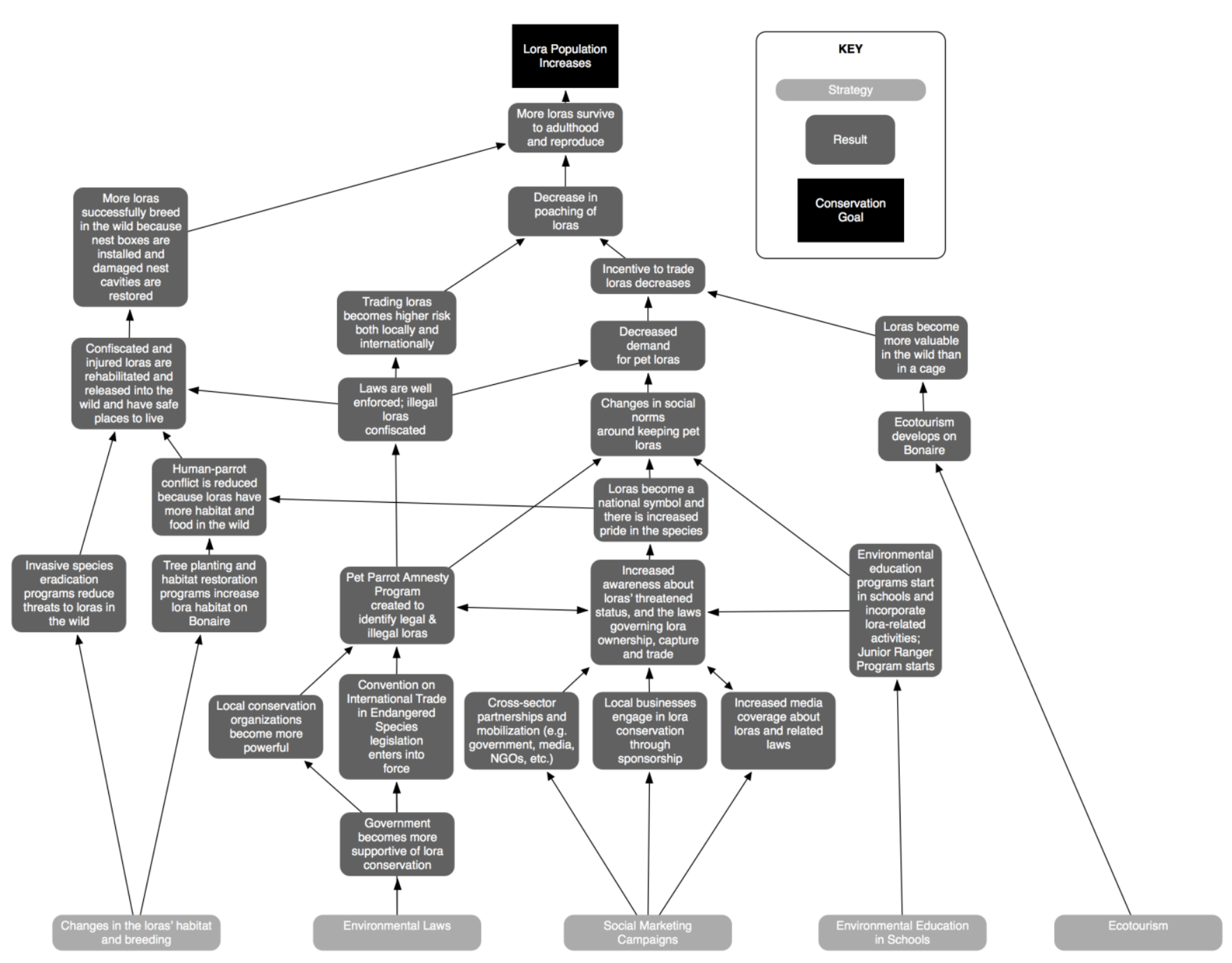

Figure 2: The original theory of change developed to understand the casual pathways by which the Rare Campaign and other factors could have influenced the lora population on Bonaire since 1997.

This article is protected by copyright. All rights reserved. 


\section{Figure 3:}
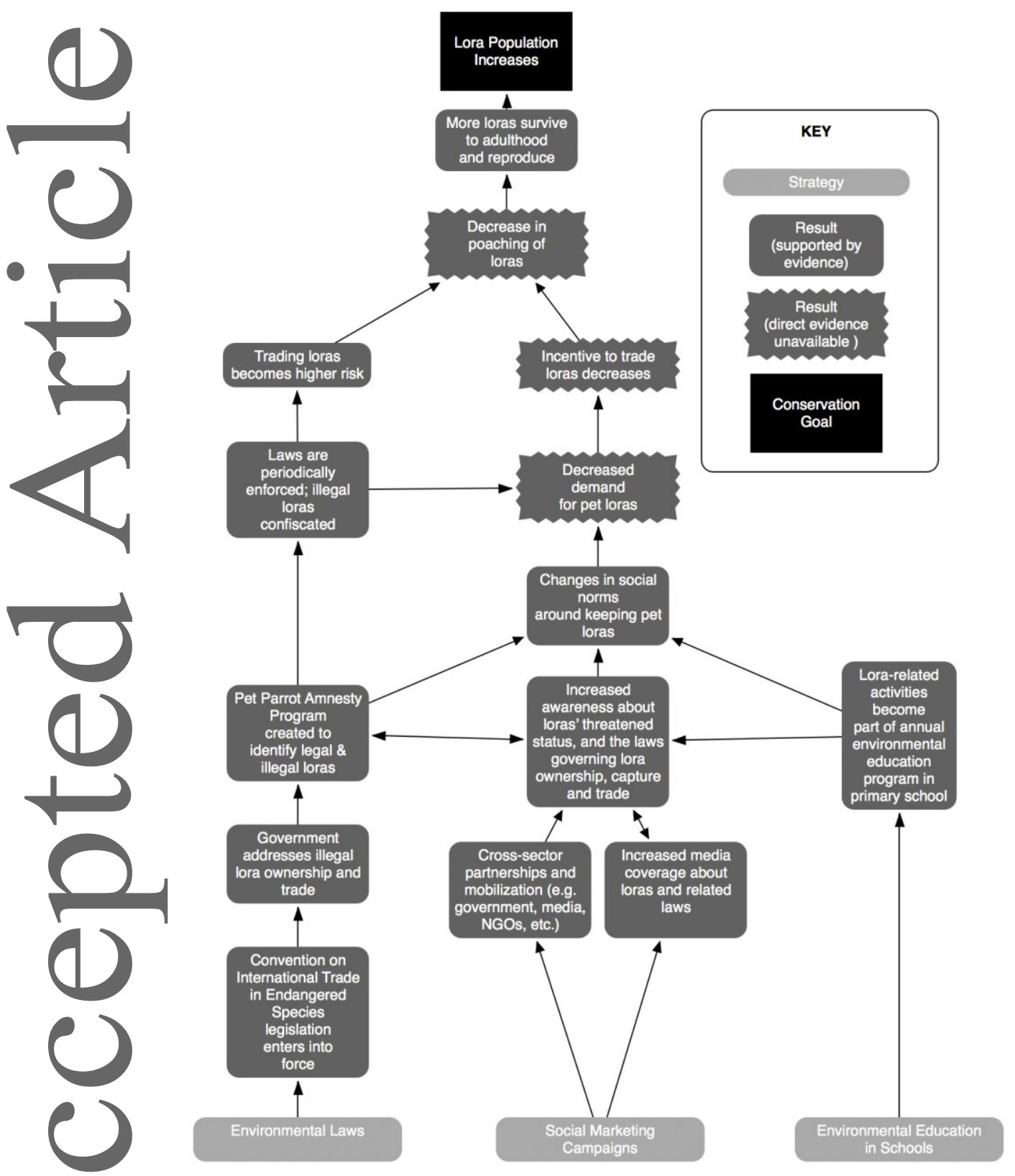

Figure 3: An overall Theory of Change showing the factors that have led to the increase in the population of the lora, or yellow-shouldered Amazon parrot, on Bonaire since 1997. This theory of change is based on our interviews and is supported by at least 3 out of 8

stakeholder groups and two-thirds of members within each group. The theory has also been triangulated with available evidence from government reports, peer-reviewed literature, and newspapers; evidence was not found to directly support elements displayed with a jagged edge.

This article is protected by copyright. All rights reserved. 